\title{
a tribute to the memory of Professor Gian Paolo Pessina
}

\section{Marcella Motta}

\section{Department of Endocrinology, University of Milan}

I feel very honored to have been invited, among qualified scientists, to pay a tribute to the memory of a great man, a dedicated mentor and an enlightened scientist, Professor Gian Paolo Pessina.

Gian Paolo passed away on October 31 at the age of 67, thus ending, at too early an age, a career rich in remarkable scientific accomplishments and of illuminating mentorship to numerous students and young investigators. I do not intend to talk about Professor Pessina's scientific achievements, which will be illustrated by more prominent and knowledgeable colleagues. I will limit my contribution, brief but heart-felt, to the human profile of his personality. I first met Gian Paolo many years ago during one of the annual meetings of the Italian Society of Physiology in Florence. At break time I am always used to going out to catch some fresh air,

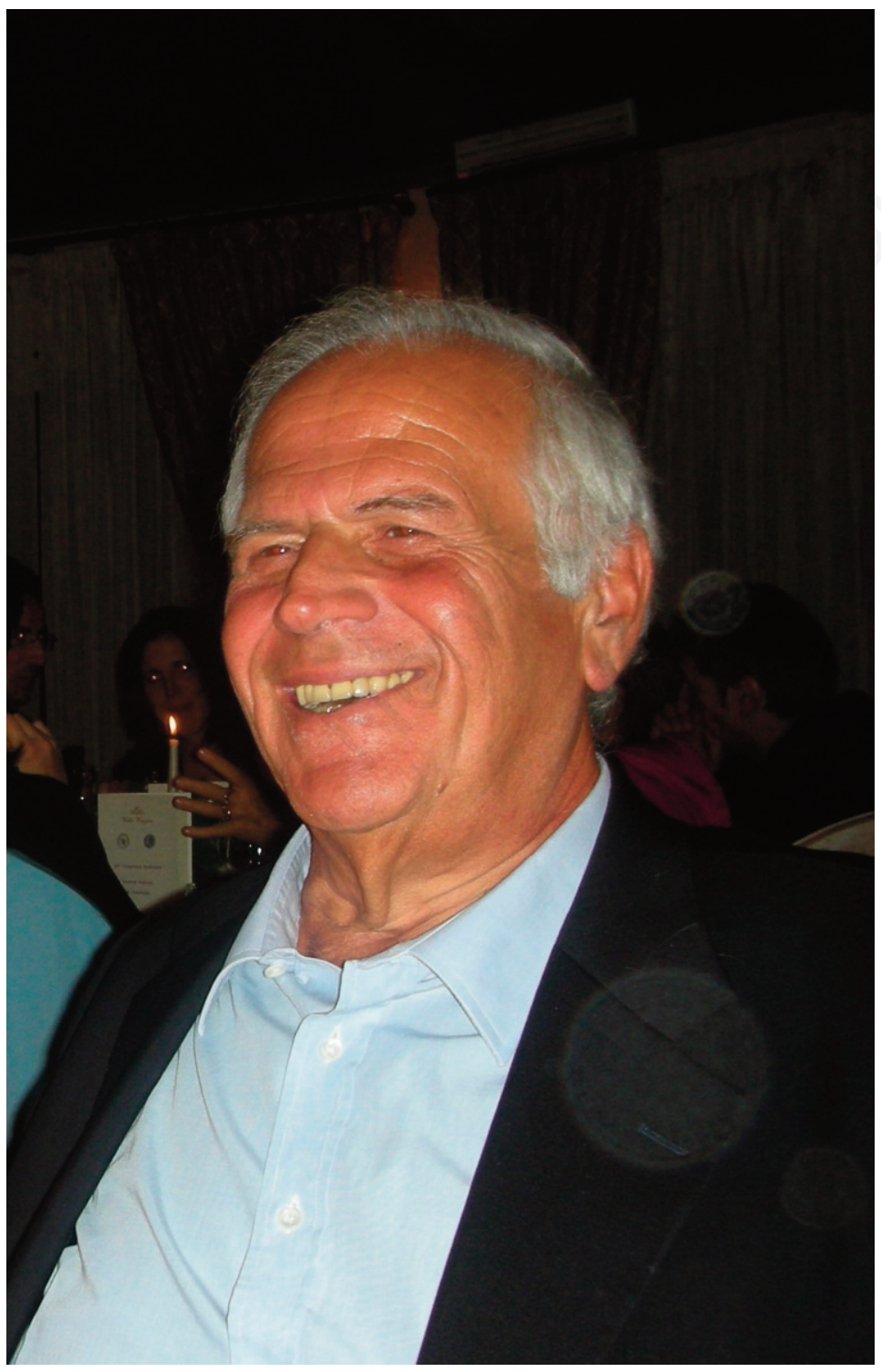

Figure. Prof. Gian Paolo Pessina. and in that occasion Gian Paolo was there too. We introduced ourselves to one another, and from the very beginning the conversation went on in a fluid and sincere manner. Since then, a close friendship between the two of us and a mutual respect of each other's ideas and concepts were born and lasted for ever. Gian Paolo was a wise and an open-minded man. No matter what the topic of our talk was (we both were interested not only in sciences, but also in music, art, literature, gardening), he never was superficial, but always showed a deep knowledge of what we were discussing about. I was always pleased to exchange opinions with him.

Before I conclude, let me spend a few words about the tight relationship between Gian Paolo and his students and fellows which delineates more efficiently the profile of the man. In the past, on several occasions I had the chance to be in his department when young investigators and students were discussing with him matters of mutual interest. I soon realized that he was highly appreciated by all his fellows for his clarity of thoughts, and his endless pursuit of excellence. He was a person kind to everybody, always ready to offer assistance and advices, but at the same time he was a severe and demanding teacher.

Gian Paolo, I and, I am sure, all who have closely interacted with you, will remember you as a scientist of extraordinary capability and humanity and a man of ethical integrity and intellectual honesty. But above all, I will remember you as a faithful, unforgettable, really a wonderful friend. 